\title{
A percepção dos jovens brasileiros sobre suas aulas de Ciências ${ }^{1}$
}

\section{Perceptions of young Brazilians about their Science classes}

\author{
Ana Maria Santos Gouw ${ }^{2}$ \\ Nelio Marco Vincenzo Bizzo ${ }^{3}$
}

\begin{abstract}
RESUMO
O desencanto dos estudantes pela carreira científica e pelas aulas de Ciências tem promovido a necessidade de identificar as percepções dos jovens em relação à ciência, suas aulas de Ciências, o papel da ciência na sociedade, dentre outros. Neste sentido, o projeto internacional The Relevance of Science Education (Rose) configura-se como uma das iniciativas que procuram responder a esta questão. Ele já foi implementado em mais de 40 países e é o objeto de estudo do trabalho aqui descrito. A pesquisa encontra-se dentro do campo da avaliação educacional. A amostra brasileira, de representatividade nacional, envolveu 2.365 estudantes, oriundos de 84 escolas. Os dados obtidos revelam que o jovem brasileiro considera a ciência escolar interessante, apesar de não ter preferência pela ciência em relação a outras disciplinas. Há uma atitude geral positiva em relação à disciplina, tanto no que se refere à sua importância como à sua utilidade. Apesar disso, tanto meninas quanto meninos têm pouco interesse em ingressar na carreira científica. A lacuna existente entre o interesse pela ciência escolar e o interesse pela carreira nos impõe a necessidade de aprofundar estudos sobre o tema.
\end{abstract}

Palavras-chave: interesse dos estudantes; avaliação educacional; ciência escolar.

DOI: $10.1590 / 0104-4060.43612$

1 A pesquisa foi financiada pelo Conselho Nacional de Desenvolvimento Científico e Tecnológico (CNPq), através do Edital Universal 14/2009, e teve apoio da Faculdade de Educação da Universidade de São Paulo.

2 Universidade Federal de São Paulo. Diadema, São Paulo, Brasil. Campus Diadema. Av. Conceição, no 329. Centro. CEP: 09920-000.E-mail: anagouw@gmail.com

3 Universidade de São Paulo. Faculdade de Educação. São Paulo, São Paulo, Brasil. Av. da Universidade, nº 308. Butantã. CEP: 05508-040.E-mail: bizzo@usp.br 


\begin{abstract}
The disenchantment of students for scientific careers and in Science classes has promoted the need to identify the perceptions of youngsters towards science, their Science classes, the role of science in society, among others. In this sense, the international project The Relevance of Science Education (Rose) appears as one of the initiatives that seek to respond to this issue. It has already been implemented in over 40 countries and it is the subject matter of the work described herein. The research is within the educational evaluation field. The nationwide representative Brazilian sample involved 2,365 students, from 84 schools. The data reveals that young Brazilians consider school science interesting, despite having no preference for science in relation to other disciplines. There is a general positive attitude towards the subject, both with respect to its importance and its usefulness. Nevertheless, both girls and boys have little interest in joining scientific careers. The gap between the interest in school science and the interest in career imposes the need for further studies on the subject.
\end{abstract}

Keywords: students' interests; educational evaluation; educational science.

\title{
Introdução
}

A pesquisa aqui descrita é parte da implementação no Brasil do projeto internacional The Relevance of Science Education (Rose), aplicado em mais de 40 países e coordenado por pesquisadores da Universidade de Oslo, Noruega. $O$ projeto surgiu como uma tentativa em responder a alguns dos dilemas enfrentados pelos pesquisadores da área de ensino de ciências: a diminuição do interesse dos jovens em seguir carreiras científicas, a diminuição do interesse pela ciência ao longo da escolaridade básica, a necessidade de se ouvir os estudantes nas propostas educacionais e a posição da educação científica face à diversidade cultural existente na sociedade. (SCHREINER; SJØBERG, 2004).

Para isso, o projeto Rose busca coletar dados de natureza atitudinal e emocional dos estudantes, abordando aspectos que podem ser importantes para o engajamento tanto na ciência escolar como na vida em geral. As experiências que o estudante tem, os tipos de interesse relacionados a conteúdos da ciência e tecnologia $(\mathrm{C} \& \mathrm{~T})$, suas visões e atitudes em relação à $\mathrm{C} \& \mathrm{~T}$ na sociedade e suas percepções acerca da ciência escolar são contemplados através de um instrumento de coleta de dados composto por 245 itens. (SCHREINER; SJØBERG, 2004).

Para os idealizadores do projeto Rose, a "[...] falta de relevância do currículo de C\&T é provavelmente uma das grandes barreiras para a compreensão do 
tema, bem como para o maior interesse no assunto", por isso, o projeto procura trazer perspectivas teóricas e empíricas para discussões mais fundamentadas sobre como melhorar o currículo e aumentar o interesse dos alunos em relação à ciência e à tecnologia. (SCHREINER; SJØBERG, 2004, p.6).

Schreiner (2006) afirma que o projeto Rose assume a perspectiva do que é relevante sob o ponto de vista do aluno e o que eles expressam ser de interesse para suas vidas. Assim, o projeto procura conhecer uma série de aspectos relacionados aos interesses, percepções, preocupações, esperanças, valores, experiências e atitudes, no que tange à ciência e tecnologia e seus planos e prioridades para o futuro.

Para Schreiner e Sjøberg (2007), a investigação dos interesses dos estudantes se faz necessária porque suas escolhas em relação ao futuro, à carreira no ensino superior ou à profissão, estão vinculadas a quanto elas serão interessantes, importantes ou significativas e a quanto elas se harmonizam com a identidade e o desenvolvimento pessoal dos jovens.

Os autores argumentam que a maior parte do conteúdo abordado nas aulas de Ciências é esquecida pelo aluno ao longo da vida. Porém, questões escolares relacionadas às atitudes possuem um efeito mais duradouro. Estudantes que desenvolveram um interesse pela ciência na escola provavelmente continuarão tendo interesse ao longo da vida. Da mesma forma, os alunos que aprenderam a odiar a ciência e a matemática na escola são propensos a evitar estes assuntos. Assim, os fatores afetivos são determinantes para a escolha de opções de futuro dos estudantes. (SCHREINER; SJØBERG, 2004).

Este artigo apresenta os resultados da aplicação do projeto Rose no Brasil em âmbito nacional. Os dados aqui apresentados estão relacionados aos diferentes aspectos da percepção dos jovens sobre suas aulas de Ciências, tais como motivação, habilidades, necessidades e interesses.

\section{O interesse dos jovens pela ciência escolar}

Sjøberg (2004, p. 7) comenta que tanto meninas quanto meninos se interessam pouco pela ciência escolar. Ele aponta que ao mesmo tempo em que os jovens demonstram interesse pela ciência real, a ciência escolar é considerada difícil e chata, sobrecarregada por "respostas certas", sem espaço para a criatividade.

Osborne, Simon e Collins (2003) consideram que o papel da educação científica formal é fomentar atitudes positivas para com a ciência, o que gera uma apreciação geral das pessoas pela ciência. Tais atitudes, uma vez formadas, são 
duradouras e difíceis de mudar, por isso, a necessidade de conhecer quais são as atitudes dos alunos brasileiros para com a ciência na escola se torna necessária.

Vázquez Alonso e Manassero Mas (2008, p. 275) destacam o fato de que o interesse dos jovens pela ciência escolar começa a diminuir na pré-adolescência, por volta dos 12 anos, na passagem do Ensino Fundamental para o Ensino Médio; o interesse e curiosidade natural da criança passam a se transformar "em desinteresse, aborrecimento e experiências de fracasso escolar", o que tem levado ao abandono das carreiras científicas.

De fato, diversas pesquisas têm relacionado o baixo interesse dos jovens em seguir as carreiras científicas diretamente às suas aulas de Ciências (AIKENHEAD, 2005; KARDASH; WALLACE, 2001; BERNARDO et al., 2008; BROK et al., 2006; DARBY, 2005). Fensham (2004, p. 2) aponta para três pontos que fazem com que a ciência escolar seja desinteressante para os alunos: “1) transmissão de conhecimentos de respostas certas; 2) conteúdo irrelevante e chato; e 3) dificuldade, em comparação a outras disciplinas".

Osborne, Simon e Collins (2003) apontaram também para a falta de desafio intelectual como um dos fatores que levam ao desinteresse dos alunos pela ciência escolar. Poucas aulas experimentais, trabalho pedagógico repetitivo e conteúdo curricular inapropriado também foram apontados por Murphy e Beggs (2003) como motivos para a falta de interesse dos alunos pelas aulas de Ciências na educação primária.

Barman et al. (1997), em uma pesquisa realizada com alunos do $5^{\circ}$ ano primário, apontam que a maioria dos alunos não vê conexão entre o que aprendem na escola e sua vida diária. Para eles, a ciência escolar precisa apresentar exemplos concretos que demonstrem sua ligação com o que os alunos fazem fora da escola, tais como a observação, a medição, etc. Ao final, apenas $9 \%$ dos alunos pesquisados foram capazes de conectar as habilidades e conhecimentos adquiridos da ciência às suas atividades cotidianas, citando como exemplos a solução de problemas, a observação, a identificação de animais e plantas, a previsão do tempo, etc.

É de se notar, entretanto, que em uma pesquisa realizada com jovens ingleses de 16 anos, Osborne e Collins (2001) verificaram que os jovens consideram o conhecimento científico como importante componente da educação. As razões apontadas foram a possibilidade de através da ciência se conhecer o mundo, conhecer seu próprio corpo, consertar coisas, além da utilidade da ciência para as pessoas e para a sociedade em geral.

Bevins, Brodie e Brodie (2005) também verificaram, em uma pesquisa realizada com jovens ingleses de 12 a 14 anos, que há interesse dos alunos na ciência, mas há também uma aparente falta de entusiasmo para com a ciência escolar, uma vez que esta presta pouca ou nenhuma atenção a questões cien- 
tíficas relacionadas com a vida diária dos alunos, além de ser pouco atrativa pedagogicamente, já que está centrada em aulas teóricas, sendo as aulas práticas as que de fato despertam o interesse dos alunos.

Em uma pesquisa realizada na Espanha com estudantes de diversas faixas etárias, Vázquez Alonso e Manassero Mas (2008) verificaram que o declínio nas atitudes dos alunos se restringe à ciência escolar, não sendo verificada em relação à imagem da ciência em si ou ao meio ambiente.

Danaia, Fitzgerald e Mckinnon (2012) relatam, em pesquisa realizada com estudantes de Ensino Médio australianos em 2001, 2005 e 2011, que os jovens raramente consideram a ciência escolar relevante para seu futuro ou para a vida cotidiana. Parece que para a maioria dos estudantes, nas três amostras, a ciência escolar pouco lida com as coisas que os jovens se preocupam ou os ajudam a tomar decisões sobre sua saúde.

Em 2005, o relatório do Eurobarômetro apontou que apenas 15\% dos europeus estão satisfeitos com a qualidade das aulas de Ciências na escola. A mesma pesquisa, realizada em 2001, verificou que o motivo pelo baixo interesse dos jovens em seguir as carreiras científicas reside no fato das aulas de Ciências na escola não serem suficientemente atraentes. (EUROPEAN COMMISSION, 2007).

Observa-se uma aparente contradição entre as atitudes dos jovens para com a ciência de modo geral e para com a ciência escolar. Algumas pesquisas apontam para o fato de que os jovens possuem atitudes positivas para com a ciência, considerando-a interessante e útil para o futuro emprego, em contrapartida com a ciência escolar, que é vista como difícil, teórica e chata. (OSBORNE; SIMON; COLLINS, 2003).

Verificamos, assim, que há uma lacuna entre a percepção do jovem em relação à ciência e à ciência escolar. A aplicação do projeto Rose em âmbito nacional no Brasil permitiu verificar se tal situação também é observada entre os jovens brasileiros.

\section{Metodologia}

A pesquisa aqui descrita está situada dentro do campo da avaliação educacional. Buriasco (2000) destaca a diversidade de objetivos da avaliação educacional atual, tais como "[...] subsidiar o processo de ensino e aprendizagem, fornecer informações sobre os alunos, professores e escolas, atuar como respaldo da certificação e da seleção e orientar na elaboração de políticas educacionais". (BURIASCO, 2000, p. 156). 
Metodologias de avaliação educacional em âmbito nacional implicam abordagens de natureza quantitativa. Sobre elas, é interessante ressaltar a escassa literatura existente no país. Gatti (2004, p. 13) declara que, apesar da pouca produção de pesquisas com esta abordagem, “[...] há problemas educacionais que para sua contextualização e compreensão necessitam ser qualificados através de dados quantitativos".

A autora considera que estudos quantitativos contextualizados por perspectivas teóricas trazem subsídios para que os fenômenos educacionais sejam tratados além dos casuísmos e "achômetros" construídos a partir do senso comum, trazendo elementos concretos para o enfrentamento de políticas, planejamento e orientação de ações pedagógicas. (GATTI, 2004, p. 26).

\section{Instrumento de coleta de dados}

A avaliação educacional descrita nesta pesquisa teve como objetivo conhecer a percepção dos estudantes sobre suas aulas de Ciências e o interesse em seguir a carreira científica. Para isso, foi realizada a aplicação do instrumento Rose, um questionário com questões fechadas que utiliza afirmações acerca da ciência e da ciência escolar, onde o aluno é convidado a assinalar seu grau de interesse em uma escala tipo Likert de quatro pontos. Tal instrumento, desenvolvido pelos organizadores do projeto na Noruega (SCHREINER; SJØBERG, 2004), foi adequado ao contexto brasileiro por Tolentino Neto (2008).

O questionário completo é composto por 245 itens distribuídos em 8 seções nomeadas por letras (A a H). No Brasil, foram incluídas 23 questões específicas sobre a religiosidade e a aceitação da evolução biológica (seções I a N). A seção que traz informações sobre as aulas de Ciências é denominada "seção F - As minhas aulas de Ciências". Ela é composta por 16 itens e abrange questões envolvendo a dificuldade em aprender ciências, a utilidade de se aprender ciências e algumas vantagens em se aprender a disciplina.

A escala Likert utilizada possui quatro opções - de "não concordo" a "concordo" - sem opção neutra. A opção por uma escala com quatro pontos e não com cinco, como são as escalas de Likert clássicas, está relacionada ao fato de que a opção neutra geralmente traz erros de interpretação: pode indicar um ponto central entre extremos, mas também falta de conhecimento ou entendimento da questão, indiferença ou mesmo falta de motivação. Assim, no caso do questionário Rose, o estudante é orientado a não responder quando não compreende a questão ou quando não quer responder a questão. (SCHREINER; SJØBERG, 2004). 
O instrumento de coleta de dados foi impresso em cadernos com folhas ópticas, onde as respostas são preparadas para a leitura através de Intelligent Character Recognition (ICR), que proporciona a captura automática de dados. Cada caderno de respostas foi personalizado com um código de barras, o que permitiu sua fácil localização, tendo em vista a natureza anônima do instrumento.

\section{População-alvo}

A população-alvo desta pesquisa é de estudantes que estão completando os estudos compulsórios e iniciando a última etapa da Educação Básica, onde deverão tomar decisões sobre seu futuro profissional. Convencionou-se que todos os países participantes do projeto Rose elegeriam a série escolar onde se esperaria encontrar idealmente os estudantes de 15 anos. No caso brasileiro, esta norma foi traduzida optando pela aplicação a jovens do primeiro ano do Ensino Médio.

Para definir uma amostra de representatividade nacional foi utilizada como referência a amostra brasileira do Programa Internacional de Avaliação de Alunos (PISA) realizado no ano de 2009, de forma que foram mantidas as mesmas características e representatividade da amostra original. Assim, o universo amostral deste estudo corresponde à amostra PISA do ano de 2009.

A opção por ter como referência a amostra PISA 2009 se deu pelo fato dela ser estatisticamente significativa da população estudantil brasileira. Além disso, há proximidade entre público-alvo da pesquisa Rose e PISA e as informações das escolas participantes do PISA 2009 podem ser acessadas através do Instituto Nacional de Estudos e Pesquisas Educacionais Anísio Teixeira (INEP).

Devido ao presente estudo ser realizado em escolas, houve a necessidade de aplicar o questionário junto a turmas de alunos e não a alunos individualmente. Desta forma, foi selecionada uma turma de $1^{\circ}$ ano de Ensino Médio em cada unidade escolar participante, com tamanho médio estimado de 30 alunos, sendo o critério de escolha a presença de alunos de 15 anos de idade em sua maioria.

\section{Tamanho amostral}

Considerando o universo amostral acima descrito, foi desenhado um plano amostral inicial envolvendo o sorteio de 160 unidades escolares distribuídas em todos os estados brasileiros. Todos os alunos das escolas sorteadas (média de 30 por escola) 
deveriam ser incluídos na amostra. Considerando uma perda de $20 \%$ das escolas sorteadas e de $10 \%$ de alunos dentro das escolas, deveriam ser pesquisadas 128 escolas e 27 alunos em cada escola, resultando em 3.456 questionários preenchidos.

As estimativas de proporções calculadas para este tamanho amostral correspondem à obtenção de estimativas com erro de amostragem entre 3 e 4 pontos percentuais (sendo o ponto $3 \mathrm{o}$ equivalente a 2.160 questionários e $\mathrm{o}$ ponto 4 o equivalente a 3.841 questionários), o que é considerado satisfatório para uma pesquisa realizada em âmbito nacional.

O período de coleta de dados ocorreu entre julho de 2010 e setembro de 2011. Os questionários foram enviados para as escolas por correio, juntamente com o Termo de Consentimento Livre e Esclarecido, indicado pelo Comitê de Ética de instituição de pesquisa responsável pelo Projeto Rose no Brasil, bem como de envelopes selados para o retorno dos questionários preenchidos.

Ao final do período de coleta obteve-se 2.365 questionários preenchidos oriundos de 84 escolas situadas em todos os estados brasileiros, número que se manteve dentro da faixa correspondente à estimativa de erro de amostragem situado entre 3 e 4 pontos percentuais previstos inicialmente. Dentre as escolas participantes da pesquisa, 96\% estão localizadas em áreas urbanas e 4\% em áreas rurais. Em relação à dependência administrativa, $88 \%$ são públicas estaduais, $4 \%$ são públicas federais e $8 \%$ privadas. Dentre os jovens participantes (respostas válidas), 57,6\% são meninas e $42,3 \%$ são meninos, com idade média de 15,39 anos de idade.

\section{Resultados e discussão}

A ciência escolar é um importante meio de fomentar o interesse dos jovens pelos temas científicos e pela carreira científica. Conhecer o que os jovens brasileiros pensam da ciência na escola poderá elucidar importantes questões relacionadas ao seu interesse pela disciplina, sua utilidade e sua relação com as opções futuras de carreira.

Para tanto, os dados serão apresentados da seguinte forma: 1) através das médias de meninos e meninas para todas as questões presentes na seção $\mathrm{F}$ e 2) através de médias de meninos e meninas para categorias (agrupamento de questões). Para a verificação de diferenças entre gênero foram utilizados testes de Mann-Whitney. Diferenças com valores de $\mathrm{p}<0,05$ foram consideradas significativas e estão destacadas nas tabelas através do uso do negrito. As médias obtidas na totalidade das 16 questões da seção F "As minhas aulas de Ciências" podem ser observadas na Tabela 1. 
TABELA 1 - MÉDIAS E TESTES DE MANN-WHITNEY PARA DIFERENÇA EM RELAÇÃO AO GÊNERO DOS ESTUDANTES PARA O GRUPO DE QUESTÕES F

\begin{tabular}{|c|c|c|c|c|c|c|}
\hline \multirow{2}{*}{ Questões: "As minhas aulas de ciências" } & \multirow{2}{*}{$\begin{array}{l}\text { Média } \\
\text { Geral }\end{array}$} & \multicolumn{2}{|c|}{ Média } & \multirow{2}{*}{$\begin{array}{c}\text { Diferença } \\
\text { (H-M) }\end{array}$} & \multirow{2}{*}{ IC 95 (Dif) } & \multirow{2}{*}{ P-valor } \\
\hline & & Homem & Mulher & & & \\
\hline $\begin{array}{l}\text { F01 - A disciplina Ciências aborda conteúdos } \\
\text { difíceis }\end{array}$ & 2,38 & 2,41 & 2,35 & 0,06 & {$[-0.03 ; 0.16]$} & 0,213 \\
\hline F02 - A disciplina Ciências é interessante & 3,17 & 3,06 & 3,26 & $-0,20$ & {$[-0.28 ;-0.12]$} & 0,01 \\
\hline $\begin{array}{l}\text { F03 - As Ciências, para mim, são bastante } \\
\text { fáceis de aprender }\end{array}$ & 2,42 & 2,46 & 2,39 & 0,07 & {$[-0.02 ; 0.15]$} & 0,11 \\
\hline $\begin{array}{l}\text { F04 - As Ciências abriram-me os olhos para } \\
\text { empregos novos e emocionantes }\end{array}$ & 2,36 & 2,39 & 2,34 & 0,05 & {$[-0.04 ; 0.14]$} & 0,194 \\
\hline $\begin{array}{l}\text { F05 - Gosto mais de Ciências do que das } \\
\text { outras disciplinas }\end{array}$ & 2,10 & 2,08 & 2,12 & $-0,04$ & {$[-0.13 ; 0.05]$} & 0,688 \\
\hline $\begin{array}{l}\text { F06 - Penso que todos deverão aprender } \\
\text { Ciências }\end{array}$ & 2,68 & 2,56 & 2,78 & $-0,22$ & {$[-0.31 ;-0.13]$} & 0,01 \\
\hline $\begin{array}{l}\text { F07 - Os conhecimentos que adquiro em } \\
\text { Ciências serão úteis na minha vida cotidiana }\end{array}$ & 3,00 & 2,83 & 3,13 & $-0,30$ & {$[-0.38 ;-0.21]$} & $\mathbf{0 , 0 1}$ \\
\hline $\begin{array}{l}\text { F08 - Penso que a ciência que eu aprendo na } \\
\text { escola melhorará as minhas oportunidades de } \\
\text { carreira }\end{array}$ & 2,75 & 2,68 & 2,81 & $-0,13$ & {$[-0.21 ;-0.04]$} & $\mathbf{0 , 0 0 4}$ \\
\hline $\begin{array}{l}\text { F09 - As Ciências tornaram-me mais crítico e } \\
\text { cético }\end{array}$ & 2,31 & 2,35 & 2,27 & 0,08 & {$[-0.01 ; 0.17]$} & 0,071 \\
\hline $\begin{array}{l}\text { F10 - As Ciências estimularam a minha } \\
\text { curiosidade acerca das coisas que ainda não } \\
\text { conseguimos explicar }\end{array}$ & 2,85 & 2,74 & 2,93 & $-0,19$ & {$[-0.28 ;-0.10]$} & $\mathbf{0 , 0 1}$ \\
\hline $\begin{array}{l}\text { F11 - As Ciências aumentaram o meu gosto } \\
\text { pela natureza }\end{array}$ & 2,76 & 2,69 & 2,82 & $-0,13$ & {$[-0.22 ;-0.04]$} & 0,007 \\
\hline $\begin{array}{l}\text { F12 - As Ciências mostraram-me a } \\
\text { importância da ciência para a forma como } \\
\text { vivemos }\end{array}$ & 2,80 & 2,69 & 2,87 & $-0,18$ & {$[-0.27 ;-0.10]$} & 0,01 \\
\hline $\begin{array}{l}\text { F13 - A ciência que aprendo na escola ensina- } \\
\text { me a cuidar melhor da minha saúde }\end{array}$ & 2,91 & 2,81 & 2,98 & $-0,17$ & {$[-0.25 ;-0.08]$} & $\mathbf{0 , 0 1}$ \\
\hline F14 - Gostaria de ser cientista & 1,98 & 2,10 & 1,89 & 0,21 & {$[0.11 ; 0.30]$} & $\mathbf{0 , 0 1}$ \\
\hline $\begin{array}{l}\text { F15 - Gostaria de aprender tanta ciência } \\
\text { quanto possível na escola }\end{array}$ & 2,43 & 2,43 & 2,42 & 0,01 & {$[-0.09 ; 0.10]$} & 0,895 \\
\hline $\begin{array}{l}\text { F16 - Gostaria de ter um emprego que lide } \\
\text { com tecnologia avançada }\end{array}$ & 2,71 & 2,89 & 2,58 & 0,31 & {$[0.22 ; 0.40]$} & 0,01 \\
\hline
\end{tabular}

FONTE: Os autores (2016).

*IC 95 - Intervalo de Confiança de 95\%. 
Vázquez Alonso e Manassero Mas (2008), que aplicaram o projeto Rose na Espanha, utilizaram como primeiro parâmetro de análise da seção $\mathrm{F}$ a média global dos alunos (média para todas as questões). A média global dos brasileiros foi de 2,60, superior à média da escala $(2,5)$ e superior ao valor atribuído aos jovens espanhóis $(2,44)$, o que indica uma atitude geral favorável em relação às aulas de Ciências.

Os jovens brasileiros consideram a disciplina de Ciências interessante e não concordam que ela aborda conteúdos difíceis. Por outro lado, eles não a consideram fácil de aprender. Assim, os resultados das três primeiras questões vão de encontro aos dados obtidos na análise geral do Rose, que apontam para o pouco interesse dos jovens pela ciência escolar e pelo fato deles a considerarem uma disciplina difícil. (SJØBERG, 2004). Por outro lado, os coordenadores do Rose verificaram que os jovens dos países desenvolvidos apresentam pouco interesse pela ciência escolar quando comparados com os jovens dos países em desenvolvimento (SCHREINER; SJØBERG, 2007), corroborando assim os dados brasileiros.

As demais questões foram analisadas em três categorias. O critério utilizado para o agrupamento foi reunir questões com a mesma orientação. Algumas destas questões foram agrupadas por outros pesquisadores, tais como Ogawa e Shimode (2004), no Japão, e Jenkins e Nelson (2005), na Inglaterra. As médias obtidas nestas categorias podem ser observadas na Tabela 2 .

TABELA 2 - MÉDIAS DE MENINAS, MENINOS E GERAL PARA CATEGORIAS DA SEÇÃO F

\begin{tabular}{lccccccc}
\hline \multirow{2}{*}{ Categorias (seção F) } & \multirow{2}{*}{$\begin{array}{c}\text { Média } \\
\end{array}$} & Geral & Homem & Mulher & $\begin{array}{c}\text { Diferença } \\
\text { (H-M) }\end{array}$ & $\begin{array}{c}\text { IC 95\% } \\
\text { (Diferença) }\end{array}$ & $\begin{array}{c}\text { P- } \\
\text { valor }\end{array}$ \\
\hline $\begin{array}{l}\text { Relação entre a disciplina e a futura } \\
\text { carreira }\end{array}$ & 2,45 & $\mathbf{2 , 5 2}$ & 2,40 & 0,12 & {$[0.05 ; 0.180]$} & 0,001 \\
$\begin{array}{l}\text { Interesse pessoal pela disciplina } \\
\begin{array}{l}\text { Vantagens diretas da aprendizagem da } \\
\text { disciplina }\end{array}\end{array}$ & 2,59 & 2,53 & $\mathbf{2 , 6 4}$ & $-0,11$ & {$[-0.18 ;-0.04]$} & 0,003 \\
& & 2,68 & $\mathbf{2 , 8 4}$ & $-0,16$ & {$[-0.22 ;-0.09]$} & 0,000 \\
\hline
\end{tabular}

FONTE: Os autores (2016).

O agrupamento das questões revelou que os meninos veem mais relações entre a ciência e a futura carreira que as meninas. Já as meninas possuem mais interesse pela ciência e veem mais vantagens diretas do aprendizado da disciplina que os meninos.

O interesse em aprender sobre ciência também foi abordado na aplicação do PISA no Brasil no ano de 2006. Quando comparadas as médias entre PISA e Rose (ambos possuem escala de Likert com 4 pontos) observamos que os dois instrumentos permitiram verificar que os alunos brasileiros possuem interesse 
pela ciência escolar. As médias atribuídas pelos alunos foram elevadas: 3,25 no PISA e 3,17 no Rose, uma diferença de apenas 2,5\% a mais do PISA.

Os dados obtidos permitiram-nos verificar que, ao contrário da tendência observada na maioria dos países desenvolvidos, os jovens brasileiros possuem interesse pela ciência escolar, apesar de não terem preferência pela ciência em relação a outras disciplinas. Há uma atitude positiva geral em relação à disciplina, tanto no que se refere à importância da disciplina como à sua utilidade.

Sobre o interesse dos jovens brasileiros em seguir a carreira científica ou terem um emprego que lide com tecnologia avançada (questões F14 e F16 do questionário), observamos que tanto meninas como meninos têm pouco interesse em ingressar na carreira científica. Já os meninos gostariam mais de ter um emprego que lide com tecnologia avançada que as meninas. A Figura 1 ilustra a diferença entre meninos e meninas em relação ao interesse pela carreira científica e tecnológica.

FIGURA 1 - O INTERESSE DE MENINOS E MENINOS PELAS CARREIRAS CIENTÍFICAS E TECNOLÓGICAS

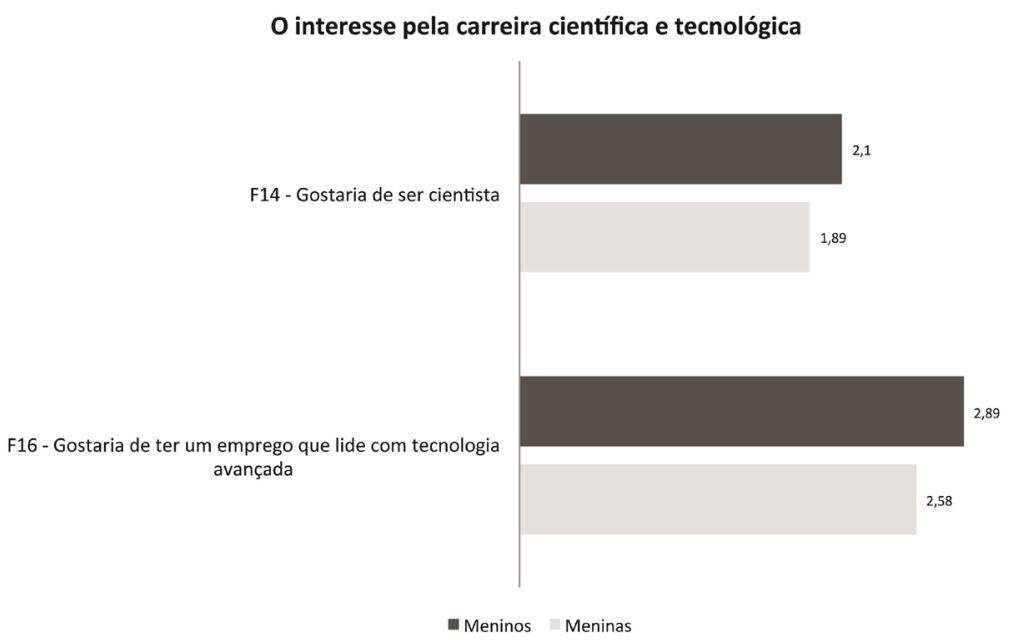

FONTE: Os autores (2016).

Algumas hipóteses tentam justificar esta tendência. Sjøberg (2001) considera 13 possíveis razões para o fato dos jovens optarem pouco pelas carreiras científicas: 1) currículo de ciências teórico, abstrato, autoritário e sem relevância para os estudantes; 2) necessidade de grande empenho para aprender ciências, fato não muito valorizado entre os jovens da atualidade; 3 ) falta de professores 
qualificados, principalmente no Ensino Médio; 4) crenças alternativas que vão de encontro à atividade científica, de cunho supersticioso, metafísico ou mesmo com apelo de "supernatural"; 5) ataques pós-modernos à ciência e à tecnologia, alicerçados em grande parte em crenças alternativas; 6) imagem estereotipada dos cientistas e engenheiros como pessoas chatas, fechadas e autoritárias; 7) desacordos entre os próprios cientistas a respeito das questões científicas que envolvem a sociedade, como o aquecimento global, a preservação ambiental, etc.; 8) falta de ética na atividade científica; 9) a não apreciação da supervalorização da ciência em atividades como a biotecnologia, que pode passar a ideia do cientista querer "brincar de Deus", ultrapassando os limites humanos; 10) mudança do papel dos cientistas, de grandes "descobridores" para colaboradores da atividade industrial e bélica; 11) mudança na imagem do cientista de herói para vilão, responsável pelos grandes males, principalmente ambientais, da humanidade; 12) a vida não glamorosa dos cientistas, que possuem pouco apelo aos jovens, que têm como modelos artistas, músicos e esportistas; e 13) a comunicação entre ciência e público em geral falha.

Não podemos nos esquivar, contudo, do papel da escola no fomento do interesse pela carreira científica. Vázquez Alonso e Manassero Mas (2009, p. 215) comentam que as

[...] escolhas por carreiras em C\&T dependem significativamente da educação científica e dos conteúdos escolares, que tanto podem desenvolver a curiosidade, o interesse e o gosto pela ciência como o contrário, $\mathrm{o}$ aborrecimento, a dificuldade e o fracasso, que conduzem ao desinteresse e rejeição. (VÁZQUEZ ALONSO; MANASSERO MAS, 2009, p. 215).

Uma pesquisa de percepção pública realizada pela Fundação de Amparo à Pesquisa do Estado de São Paulo (FAPESP) apontou para a necessidade de estabelecer relações entre o entendimento dos jovens sobre o papel da ciência e tecnologia na sociedade e sua relação com a opção ou não pela carreira científica. Para os autores, a carreira científica é frequentemente mitificada, o que pode influenciar na tomada de decisões dos jovens. (FAPESP, 2011).

Neste sentido, em estudo realizado nas cidades de Bogotá, Buenos Aires, Lima, Madri, Montevidéu e São Paulo, 87\% dos estudantes pesquisados declararam que desejam prosseguir os estudos após o término da Educação Básica, sendo a área de conhecimento de maior interesse as Ciências Sociais (28,4\%). Esta situação foi observada na cidade de São Paulo, onde 22,9\% declararam interesse pela área de Ciências Sociais, 21\% pelas Humanidades, 18,8\% pela 
Engenharia e Tecnologia, 8,4\% pelas Ciências Médicas e 2,7\% pelas Ciências Exatas e Naturais, sendo que 26,3\% declararam que ainda não sabiam. (DELEMMENE, 2011).

As médias obtidas pelos jovens brasileiros aproximam-se das médias obtidas pelos jovens dos países com Índice de Desenvolvimento Humano (IDH) menor. Os jovens finlandeses, que são conhecidos como tendo grande proficiência em ciências (OECD, 2007), possuem pouco interesse pela disciplina de modo geral. Tal dado foi observado tanto na aplicação do Rose como na aplicação do PISA 2006. Apenas em três questões da seção F do questionário Rose (F7, F2 e F8) as médias foram um pouco acima da média da escala. Nas demais questões os finlandeses valoraram as questões da seção $\mathrm{F}$ abaixo de 2,5 (OECD, 2007; LAVONEN et al., 2005).

A pesquisa Rose aqui apresentada apontou que o jovem brasileiro considera a ciência escolar interessante, o que já é um princípio para o aprofundamento da questão da falta de interesse pela carreira científica. O interesse pela ciência escolar é um dos caminhos trilhados para se chegar à ciência acadêmica. Resta-nos averiguar em que momento deste percurso ou que elementos nele presentes influenciam os jovens na determinação de suas opções de futuro.

\section{Considerações finais}

Este trabalho apresentou pesquisas que relacionam o baixo interesse dos jovens em seguir as carreiras científicas diretamente às aulas de Ciências. A ciência escolar tem sido apontada como desinteressante para alunos de diversos países e as justificativas envolvem seu caráter excessivamente teórico e abstrato, o que a torna difícil e desconectada da realidade dos jovens. (AIKENHEAD, 2005; KARDASH; WALLACE, 2001; BERNARDO et al., 2008; BROK et al., 2006; DARBY, 2005, VÁZQUEZ ALONSO; MANASSERO MAS, 2008).

Em contrapartida a esta tendência, os jovens brasileiros consideram a ciência escolar interessante e apresentam uma atitude positiva em relação a ela, apesar de não terem preferência por ela. Entretanto, tanto meninas como meninos apresentam pouco interesse em ingressar na carreira científica. Já os meninos gostariam mais de ter um emprego que lide com tecnologia avançada que as meninas.

Como o ponto de partida para o ingresso na carreira científica é o interesse pela ciência escolar, verificamos que as percepções do jovem brasileiro diferem das dos jovens de países desenvolvidos. O jovem brasileiro é interessado de 
modo geral pelas ciências, mesmo apresentando baixa proficiência nos assuntos relacionados ao tema. (OECD, 2007). Assim, os dados aqui apresentados indicam um cenário futuro positivo para o estabelecimento de uma formação científica sólida, que promova o engajamento dos estudantes na carreiras científicas. Resta-nos, entretanto, compreender a lacuna existente entre o interesse pela disciplina e o pouco interesse pela carreira. Estudos futuros poderão contribuir para ações que estimulem o ingresso do brasileiro nas ciências e o aumento da compreensão dos jovens sobre ela.

\section{REFERÊNCIAS}

AIKENHEAD, G. S. Research Into STS Science Education. Educación Química, v. 16, p. 384-397, 2005.

BARMAN, C. R. et al. Fifth grade students' perceptions about scientists and how they study and use science. In: AETS CONFERENCE PROCEEDINGS. Anais... 1997.

BERNARDO, A. B. I. et al. Students' perceptions of science classes in the Philippines. Asia Pacific Education Review, v. 9, n. 3, p. 285-295, Aug. 2008.

BEVINS, S.; BRODIE, M.; BRODIE, E. A study of UK secondary school students' perceptions of science and engineering. In: EUROPEAN EDUCATIONAL RESEARCH ASSOCIATION ANNUAL CONFERENCE. Anais... Dublin: Sheffield Hallam University, 2005.

BROK, P. D.; FISHER, D.; RICKARDS, T.; BULL, E. Californian Science Students' Perceptions of their Classroom Learning Environments. Educational Research and Evaluation: An International Journal on Theory and Practice, v. 12, n. 1, p. 3-25, 2006.

BURIASCO, R. L. C. Algumas considerações sobre Avaliação Educacional. Estudos em Avaliação Educacional, v. 22, p. 155-178, 2000.

DANAIA, L.; FITZGERALD, M.; MCKINNON, D. Students' Perceptions of High School Science: What has Changed Over the Last Decade? Research in Science Education, 14 set. 2012.

DARBY, L. Science Students' Perceptions of Engaging Pedagogy. Research in Science Education, v. 35, n. 4, p. 425-445, Dec. 2005.

DELEMMENE, D. Los jóvenes y sus esdudios futuros. In: Los estudiantes y la ciencia: encuesta a jóvenes iberoamericanos. Buenos Aires: Organización de Estados Iberoamericanos para la Educación, la Ciencia y la Cultura, 2011. 286 p. 
EUROPEAN COMMISSION. Science Education NOW: A Renewed Pedagogy for the Future of Europe. Luxembourg: Office for Official Publications of the European Communities, 2007, 22 p.

FAPESP. Percepção pública da ciência e da tecnologia no Estado de São Paulo. In: FAPESP (Ed.). Indicadores de Ciência, Tecnologia e Inovação em São Paulo - 2010. São Paulo: FAPESP, 2011. p. 1-52.

FENSHAM, P. J. Engagement with Science: An international issue that goes beyond knowledge. In: SCIENCE AND MATHEMATICS EDUCATION CONFERENCE SERIES. Anais... Dublin: 2004. Disponível em: <www.dcu.ie/smec/plenary/Fensham, Peter.pdf>. Acesso em: 21 out. 2015.

GATTI, B. A. Estudos quantitativos em educação. Educação e Pesquisa, v. 30, n. 1, p. 11-30, abr. 2004.

JENKINS, E. W.; NELSON, N. W. Important but not for me: students' attitudes towards secondary school science in England. Research in Science \& Technological Education, v. 23, n. 1, p. 41-57, 2005.

KARDASH, C. M.; WALLACE, M. L. The Perceptions of Science Classes Survey: What Undergraduate Science Reform Efforts Really Need to Address. Journal of Educational Psychology, v. 93, n. 1, p. 199-210, 2001.

LAVONEN, J.; JUUTI, K.; UITTO, A.; MEISALO, V.; BYMAN, R. Attractiveness of science education in the Finnish comprehensive school. In: MANNINEN, A.; MIETTINEN, K.; KIVINIEMI, K. (Ed.). Research Findings on Young People's Perceptions of Technology and Science Education: Mirror results and good practice. Hensinki: Technology Industries of Finland, 2005. p. 5-30.

MURPHY, C.; BEGGS, J. Children's perceptions of school science. School Science Review, v. 84, n. 308, p. 109-116, 2003.

OECD. Organização para Cooperação e Desenvolvimento Econômicos. PISA 2006 Competências em ciências para o mundo de amanhã - Volume 1: Análise. Ed Moderna/ OECD Publishing, 2007. v. 1. 404 p.

OGAWA, M.; SHIMODE, S. Three distinctive groups among japanese students in terms of their school science preference: from preliminary analysis of japanese data of an international survey "The Relevance of Science Education" (Rose). Journal of Science Education in Japan, v. 28, n. 4, p. 1-11, 2004.

OSBORNE, J.; COLLINS, S. Pupils' views of the role and value of the science curriculum: A focus-group study. International Journal of Science Education, v. 23, n. 5, p. 441-467, May 2001.

OSBORNE, J.; SIMON, S.; COLLINS, S. Attitudes towards science: a review of the literature and its implications. International Journal of Science Education, v. 25, n. 9, p. 1049-1079, Sep. 2003. 
SCHREINER, C. Exploring a Rose-garden: norwegian youth's orientations towards science - seen as signs of late modern identities. 317 p. Tese (Doctor Scientiarum) Faculty of Education, University of Oslo, 2006.

SCHREINER, C.; SJØBERG, S. Sowing the Seeds of Rose. Acta Didactica 4/2004. 2004.

SCHREINER, C.; SJØBERG, S. Science education and youth's identity construction two incompatible projects? In: CORRIGAN, D.; DILLON, J.; GUNSTONE, R. (Ed.). The Re-emergence of Values in the Science Curriculum. Rotterdam: Sense Publishers, 2007. p. 1-16.

SJØBERG, S. Science and Technology in Education - Current Challenges and Possible Solutions. In: JENKINS, E. W. (Ed.). Innovations in Science and Technology Education (Vol. VIII). Paris: UNESCO, United Nations Educational, Science and Cultural Organization, 2001. p. 1-13.

SJØBERG, S. Science Education: The voice of the learners. Brussels, 2004. Disponível em: <http://roseproject.no/network/countries/norway/eng/nor-sjoberg-eu2004.pdf>. Acesso em: 21 out. 2015.

TOLENTINO NETO, L. C. B. DE. Os interesses e posturas de jovens alunos frente às ciências: resultados do Projeto Rose aplicado no Brasil. 2008. 172 p. Tese (Doutorado em Educação) - Faculdade de Educação, Universidade de São Paulo, São Paulo, 2008.

VÁZQUEZ ALONSO, Á.; MANASSERO MAS, M. A. El declive de las actitudes hacia la ciencia de los estudiantes: un indicador inquietante para la educación científica. Rev. Eureka Enseñ. Divul. Cien., v. 5, n. 3, p. 274-292, 2008.

VÁZQUEZ ALONSO, Á.; MANASSERO MAS, M. A. La vocación científica y tecnológica: predictores actitudinales significativos. Rev. Eureka Enseñ. Divul. Cien., v. 6, n. 2, p. 213-231, 2009.

Texto recebido em 21 de outubro de 2015 .

Texto aprovado em 27 de março de 2016. 